\title{
Lyapunov-Based Control for Suppression of Wind-Induced Galloping in Suspension Bridges
}

\author{
Naif B. Almutairi, Mohamed Zribi, and Mohamed Abdel-Rohman \\ College of Engineering and Petroleum, Kuwait University, P.O. Box 5969, Safat 13060, Kuwait \\ Correspondence should be addressed to Naif B. Almutairi, naif.ku@ku.edu.kw
}

Received 10 March 2011; Accepted 25 April 2011

Academic Editor: Paulo Batista Gonçalves

Copyright (C) 2011 Naif B. Almutairi et al. This is an open access article distributed under the Creative Commons Attribution License, which permits unrestricted use, distribution, and reproduction in any medium, provided the original work is properly cited.

This paper investigates the suppression of galloping in a suspension bridge due to wind loads. The galloping phenomenon can be destructive due to the high-amplitude oscillations of the structure. Two controllers are proposed to generate the control force needed to suppress the vertical galloping in the suspended cables and in the bridge deck. SIMULINK software is used to simulate the controlled system. The simulation results indicate that the proposed controllers work well. In addition, the performance of the system with the proposed controllers is compared to the performance of the system controlled with a tuned mass damper.

\section{Introduction}

Suspension bridges are one of the most popular types of bridges. Very long spans of suspension bridges are being planned [1]. Long, suspended steel cables such as those used in suspension bridges are prone to vibrations induced by wind and moving loads [2-6]. When suspended cables are subjected to wind disturbance, the system behaves nonlinearly due to its flexibility and because there is coupling between the motion of the bridge deck and the motion of the suspended cable.

The wind forces exerted on the cables and the bridge deck are complex. The aerodynamic stability of the cables and the bridge deck depends on many parameters including the wind velocity, the shape, and the size of the cross-sections and the angles of attack. When the wind velocity exceeds a certain critical value, the oscillations of the cable and/or the bridge deck will increase until a steady state response is achieved. This can be quite destructive to the structure due to the large amplitude of the oscillations. The aerodynamic instability of the bridge deck could occur simultaneously in both the torsional and vertical vibrational modes; this is called flutter and occurs when the torsional stiffness 
is close in magnitude to the flexural stiffness [7]. Aerodynamic instability can also occur exclusively in the vertical mode if the torsional stiffness is much larger than the flexural stiffness, and this form is called galloping. In this paper, we will consider only the galloping instability for a suspension bridge where changing the shape or size of the cross-sections is difficult.

The occurrence of galloping is difficult to predict. The effect of the galloping phenomenon can be quite destructive, due to the high-amplitude oscillations of the structure in the direction perpendicular to the mean wind direction [8]. For structures with low damping such as suspended cables, suspension bridges, or tall buildings, galloping can easily occur at low, steady or unsteady wind speeds [9]. The nonlinearity behavior of the suspended bridge under wind excitation can cause internal resonances which affect the safety of the structures $[7,10,11]$.

Galloping of suspended cables due to resonant harmonic loading has been studied in $[10,11]$ while galloping due to wind effects was studied in [12]. It has been shown by AbdelRohman in [8] that increasing the damping is a very effective factor in increasing the critical wind speed at which galloping occurs. Attempts to introduce passive or semiactive damping into stay cables were made in [13-18].

In this paper, we proposed two active control schemes to suppress the galloping due to wind loading in suspension bridges. The designs of both controllers are based on Lyapunov theory; the proposed controllers guarantee the asymptotic stability of the controlled suspension bridge.

The paper is organized as follows. The dynamic model of the suspension bridge subject to wind forces is presented in Section 2. In Section 3, a SIMULINK model is presented for each subsystem of the suspension bridge. In Section 4, two state feedback controllers are proposed. Simulation results are given and discussed in Section 5. Finally, some concluding remarks are given in Section 6.

In the sequel, we denote by $W^{T}$ the transpose of a matrix or a vector $W$. We use $W>$ $0(W<0)$ to denote a positive- (negative-) definite matrix $W$. Sometimes, the arguments of a function are omitted in the analysis when no confusion can arise.

\section{Equations of Motion of the System}

The derivation of the basic equations of motion of the suspended cables subject to wind forces can be found in $[12,17,19,20]$. For ease of presentation, the dynamic model is rederived in this paper.

Using the displacement directions defined in Figure 1, the general equations of motion are

$$
\begin{gathered}
\frac{\partial}{\partial s}\left[\left(T_{o}+\tau\right) \frac{\partial(x+U)}{\partial s}\right]=m_{c} \frac{\partial^{2} U}{\partial t^{2}} \\
\frac{\partial}{\partial s}\left[\left(T_{o}+\tau\right) \frac{\partial(y+V)}{\partial s}\right]=-m_{c} g+m_{c} \frac{\partial^{2} V}{\partial t^{2}}+c \frac{\partial V}{\partial t}+f_{v}(s, t) \\
\frac{\partial}{\partial s}\left[\left(T_{o}+\tau\right) \frac{\partial W}{\partial s}\right]=m_{c} \frac{\partial^{2} W}{\partial t^{2}}+c \frac{\partial W}{\partial t}+f_{w}(s, t)
\end{gathered}
$$




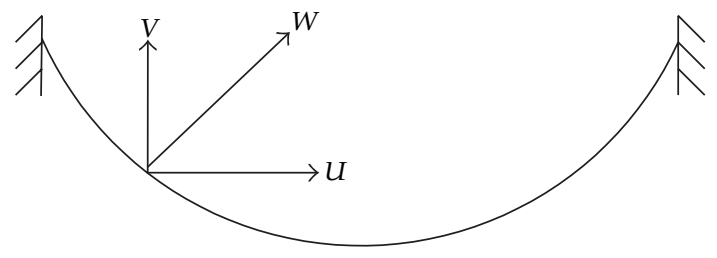

Figure 1: Displacement directions of the suspended cables.

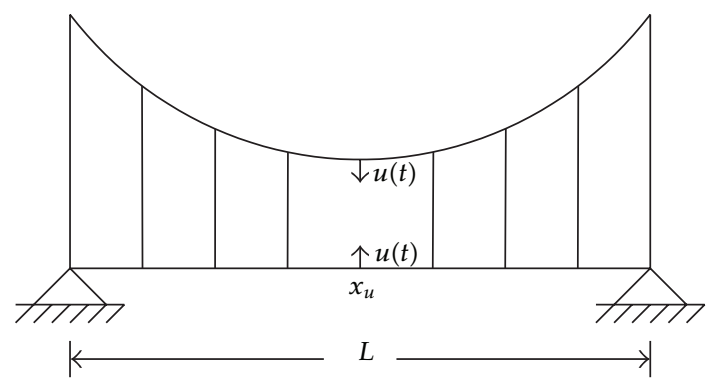

Figure 2: Suspension bridge model.

where $s$ is the spatial coordinate along the cable curved length (which is $\lambda$ ), $t$ is the time, $x(s$ ) is the horizontal coordinate along the cable span, $y(s)$ is the equation of the cable static profile, $U(s, t), V(s, t)$, and $W(s, t)$ are, respectively, the displacements of the cable at location $s$ in the horizontal, vertical, and transversal directions, $T_{o}$ is the static tension, $\tau$ is the additional dynamic tension in the cable, $c$ is the damping coefficient, $m_{c}$ is the mass of the cable per unit length, $g$ is the gravitational force, and $f_{v}(s, t)$ and $f_{w}(s, t)$ are the external loading per unit length in the vertical and transverse directions, respectively.

The nonlinear strain-displacement relationship during the deformation of the cable [20] is given by

$$
\frac{\tau}{E A}=\frac{d s^{\prime}-d s}{d s}
$$

where $E$ is the modulus of elasticity, $A$ is the cross-section area of the cable, $d s^{\prime}$ is the deformed cable segment, and $d s$ is the undeformed cable segment.

The variables $d s^{\prime}$ and $d s$ are defined such that

$$
\begin{gathered}
d s^{\prime 2}=(d x+\partial U)^{2}+(d y+\partial V)^{2}+(\partial W)^{2} \\
d s^{2}=d x^{2}+d y^{2} .
\end{gathered}
$$

The two-hinged bridge deck is suspended from the cables using vertical hangers located at $s=s_{i}$ as shown in Figure 2. $L$ is the length of the bridge deck and $u(t)$ is the active control force installed at the general location $x=x_{u}$ along the bridge.

Based on the assumption of a small curvature regime and neglecting the horizontal motion $U(s, t)$ (which can be safely disregarded because there is zero longitudinal loading 
[17]), the equations of motion from the static equilibrium position of the cable and the bridge can be simplified as follows:

$$
\begin{aligned}
\frac{\partial}{\partial s}\left[\left(T_{o}+\tau\right) \frac{\partial W}{\partial s}\right]= & m_{c} \frac{\partial^{2} W}{\partial t^{2}}+c \frac{\partial W}{\partial t}+f_{w}(s, t), \\
\frac{\partial}{\partial s}\left[\left(T_{o}+\tau\right) \frac{\partial(y+V)}{\partial s}\right]= & -\left(m_{c}+m_{b}\right) g+m_{c} \frac{\partial^{2} V}{\partial t^{2}}+c \frac{\partial V}{\partial t}+f_{v}(s, t) \\
& -\sum_{i=1}^{N_{1}} k_{i}\left(Z_{i}-V_{i}\right) \delta\left(s-s_{i}\right)+u(t) \delta\left(x-x_{u}\right), \\
E I \frac{\partial^{4} Z}{\partial x^{4}}+c_{b} \frac{\partial Z}{\partial t}+m_{b} \frac{\partial^{2} Z}{\partial x^{2}}= & f_{b}(x, t)-\sum_{i=1}^{N_{1}} k_{i}\left(Z_{i}-V_{i}\right) \delta\left(x-x_{i}\right)-u(t) \delta\left(x-x_{u}\right),
\end{aligned}
$$

where $E I$ is the flexural rigidity of the bridge deck, $c_{b}$ and $m_{b}$ are, respectively, the damping and mass per unit length of the bridge deck, $k_{i}$ is the stiffness of the vertical hangers (each located at $x_{i}$ and $\left.s_{i}\right), Z(x, t)$ is the vertical response of the bridge deck, $Z_{i}$ and $V_{i}$ indicate the response of the bridge deck and the suspended cables at $x=x_{i}$ and $s=s_{i}$, respectively, and the $\delta(\cdot)$ is the Dirac-Delta function which is used to introduce, into the differential equations, the active control force $u(t)$. The forces $f_{w}, f_{v}$, and $f_{b}$ are, respectively, the lateral and vertical wind forces on the suspended cable and the vertical wind force on the bridge deck.

Previous studies have shown that locating the control force at the most flexible location of the structure provides the most feasible and optimal performance of the controlled structure as was shown by Abel-Rohman in [21]. Thus, we set $x_{u}=0.5 \mathrm{~L}$ (see Figure 2).

The displacement functions $W(s, t), V(s, t)$, and $Z(s, t)$ are considered to be the contribution of the first modes of vibrations and are assumed to take the forms

$$
\begin{gathered}
W(s, t)=\lambda(s) W(t), \\
V(s, t)=\phi(s) V(t), \\
Z(x, t)=\eta(x) B(t),
\end{gathered}
$$

where $\lambda(s)$ and $\phi(s)$ are, respectively, the cable first mode shapes in the transversal and vertical directions, which can be determined using linear theory of cables [20] and satisfy the following boundary conditions:

$$
\begin{gathered}
\lambda(s)=\sin \left(\frac{\pi s}{l}\right), \\
\phi(s)=\frac{k_{o}}{\Omega^{2}}\left(1-\tan \left(\frac{\Omega}{2}\right) \sin \left(\frac{\Omega s}{l}\right)-\cos \left(\frac{\Omega s}{l}\right)\right),
\end{gathered}
$$


where $k_{o}$ is a constant chosen to make $\phi(s)=1$ at the midspan of the cable, $s=(\lambda / 2)$. The parameter $\Omega$ is computed from the following relations:

$$
\begin{aligned}
& \tan \left(\frac{\Omega}{2}\right)=\frac{\Omega}{2}-\frac{4}{\lambda^{2}}\left(\frac{\Omega}{2}\right)^{3}, \\
& \lambda^{2}=L\left(\frac{E A}{H l}\right) \times\left(\frac{m g L}{H}\right)^{2} .
\end{aligned}
$$

Here, the terms $m g L$ and $H$ denote the vertical weight on the cable and the horizontal component of the static tension $T_{o}$, respectively. The force $H$ is obtained from the static equilibrium of the cable as follows:

$$
H=\frac{m g L^{2}}{8 y_{c}}
$$

in which $y_{c}$ is the sag in the cable profile of which is given by the equation:

$$
y_{c}=\frac{m g L^{2}}{2 H}\left(\frac{x}{L}-\frac{x^{2}}{L^{2}}\right) .
$$

For a two-hinged bridge deck, the mode shape $\eta(x)$ can be assumed to take the form

$$
\eta(x)=\sin \left(\frac{\pi x}{L}\right)
$$

Substituting (2.5) into (2.4) and applying an integral transformation one obtains the equations of motion for the suspended cable in the transverse and vertical directions and for the vertical motion of the bridge deck as follows:

$$
\begin{gathered}
\ddot{W}+2 \zeta_{c} \omega_{w} \dot{W}+\omega_{w}^{2} W+c_{5} W V+c_{6} W V^{2}+c_{7} W^{3}=F_{W}(t), \\
\ddot{V}+2 \zeta_{c} \omega_{v} \dot{V}+\omega_{v}^{2} V+c_{1} V^{2}+c_{2} W^{2}+c_{3} V^{3}+c_{4} V W^{2}+F_{V}(t)=d_{1} B+d_{2} V+c_{11} u(t), \\
\ddot{B}+2 \zeta_{b} \omega_{b} \dot{B}+\omega_{b}^{2} B=F_{B}(t)+c_{8} B+c_{9} V-c_{10} u(t)
\end{gathered}
$$

in which $\zeta_{c}$ is the damping ratio in the suspended cable, $\omega_{w}$ and $\omega_{v}$ are, respectively, the natural frequencies of the cable in $W$ and $V$ directions, $\zeta_{b}$ is the damping ratio in the bridge deck, and $\omega_{b}$ is the natural frequency of the bridge deck. 
Expressions of the forces $F_{W}(t), F_{V}(t)$, and $F_{B}(t)$ in the above equations are given in [17] as follows:

$$
\begin{aligned}
F_{W}(t)= & C_{w o}+C_{w 1} \dot{W}+C_{w 2} \dot{W}^{2}+C_{w 3} \dot{V}+C_{w 4} \dot{W} \dot{V}+C_{w 5} \dot{V}^{2}+C_{w 6} \dot{V}^{3}+C_{w 7} \dot{V}^{3} \dot{W} \\
& +C_{w 8} \dot{V}^{3} \dot{W}^{2}+C_{w 9} \dot{V}^{3} \dot{W}^{3}+C_{w 10} \dot{V}^{4}+C_{w 11} \dot{V}^{4} \dot{W}+C_{w 12} \dot{V}^{4} \dot{W}^{2}+C_{w 13} \dot{V}^{4} \dot{W}^{3} \\
& +C_{w 14} \dot{V}^{5}+C_{w 15} \dot{V}^{5} \dot{W}+C_{w 16} \dot{V}^{5} \dot{W}^{2}+C_{w 17} \dot{V}^{5} \dot{W}^{3}+C_{w 18} \dot{V}^{6}+C_{w 19} \dot{V}^{6} \dot{W} \\
& +C_{w 20} \dot{V}^{6} \dot{W}^{2}+C_{w 21} \dot{V}^{6} \dot{W}^{3}+C_{w 22} \dot{V}^{7}+C_{w 23} \dot{V}^{7} W+C_{w 24} \dot{V}^{7} \dot{W}^{2}+C_{w 25} \dot{V}^{7} \dot{W}^{3}, \\
F_{V}(t)= & C_{v o}+C_{v 1} \dot{W}+C_{v 2} \dot{W}^{2}+C_{v 3} \dot{V}+C_{v 4} \dot{W} \dot{V}+C_{v 5} \dot{V}^{2}+C_{v 6} \dot{V}^{3}+C_{v 7} \dot{V}^{3} \dot{W} \\
& +C_{v 8} \dot{V}^{3} \dot{W}^{2}+C_{v 9} \dot{V}^{3} \dot{W}^{3}+C_{v 10} \dot{V}^{4}+C_{v 11} \dot{V}^{4} \dot{W}+C_{v 12} \dot{V}^{4} \dot{W}^{2}+C_{v 13} \dot{V}^{4} \dot{W}^{3} \\
& +C_{v 14} \dot{V}^{5}+C_{v 15} \dot{V}^{5} \dot{W}+C_{v 16} \dot{V}^{5} \dot{W}^{2}+C_{v 17} \dot{V}^{5} \dot{W}^{3}+C_{v 18} \dot{V}^{6}+C_{v 19} \dot{V}^{6} \dot{W} \\
& +C_{v 20} \dot{V}^{6} \dot{W}^{2}+C_{v 21} \dot{V}^{6} \dot{W}^{3}+C_{v 22} \dot{V}^{7}+C_{v 23} \dot{V}^{7} W+C_{v 24} \dot{V}^{7} \dot{W}^{2}+C_{v 25} \dot{V}^{7} \dot{W}^{3}, \\
F_{B}(t)= & c_{12} \dot{B}+c_{13} \dot{B} B
\end{aligned}
$$

where the coefficients $C_{w i}$ and $C_{v i}$ are functions of the basic wind speed $U_{o}$.

\section{Simulation of the Uncontrolled Suspension Bridge Model Using SIMULINK}

The dynamic model of the uncontrolled suspension bridge is simulated using the SIMULINK software. At first, a SIMULINK model is built for each subsystem of the suspension bridge. Then, the SIMULINK model subsystems are combined to simulate the overall system.

\subsection{SIMULINK Model for the Unsuspended Bridge}

The response of the bridge alone is obtained by simulating (2.13) with $c_{8}, c_{9}$, and, $c_{10}$ set to zero. Galloping occurs when $c_{12}>2 \zeta_{b} \omega_{b}$, and therefore the critical wind speed is calculated to be 10.39 (m/sec) [17]. The SIMULINK model of the unsuspended bridge is shown in Figure 3.

\subsection{SIMULINK Model for the Suspended Cable Alone}

If the cable is constructed alone, then the transverse and vertical responses of the suspended cable are obtained by simulating (2.11) and (2.12) with $d_{1}$ and $c_{11}$ set to zero. The critical wind speed of the cables is calculated to be $7.30(\mathrm{~m} / \mathrm{sec})$ [17]. The SIMULINK model of the suspended cable is shown in Figure 4 while the wind forces are simulated in Figure 5. 


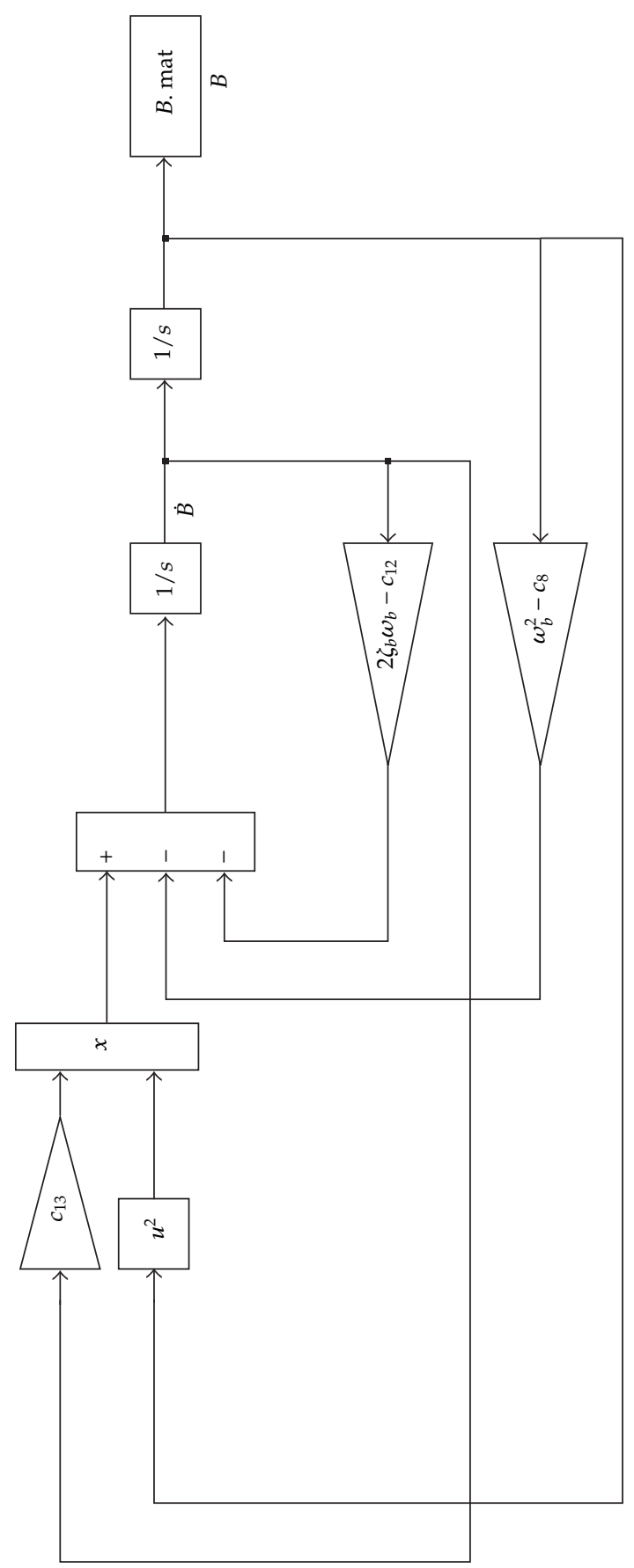

Figure 3: SIMULINK model of the unsuspended bridge including wind force $F_{B}(t)$. 


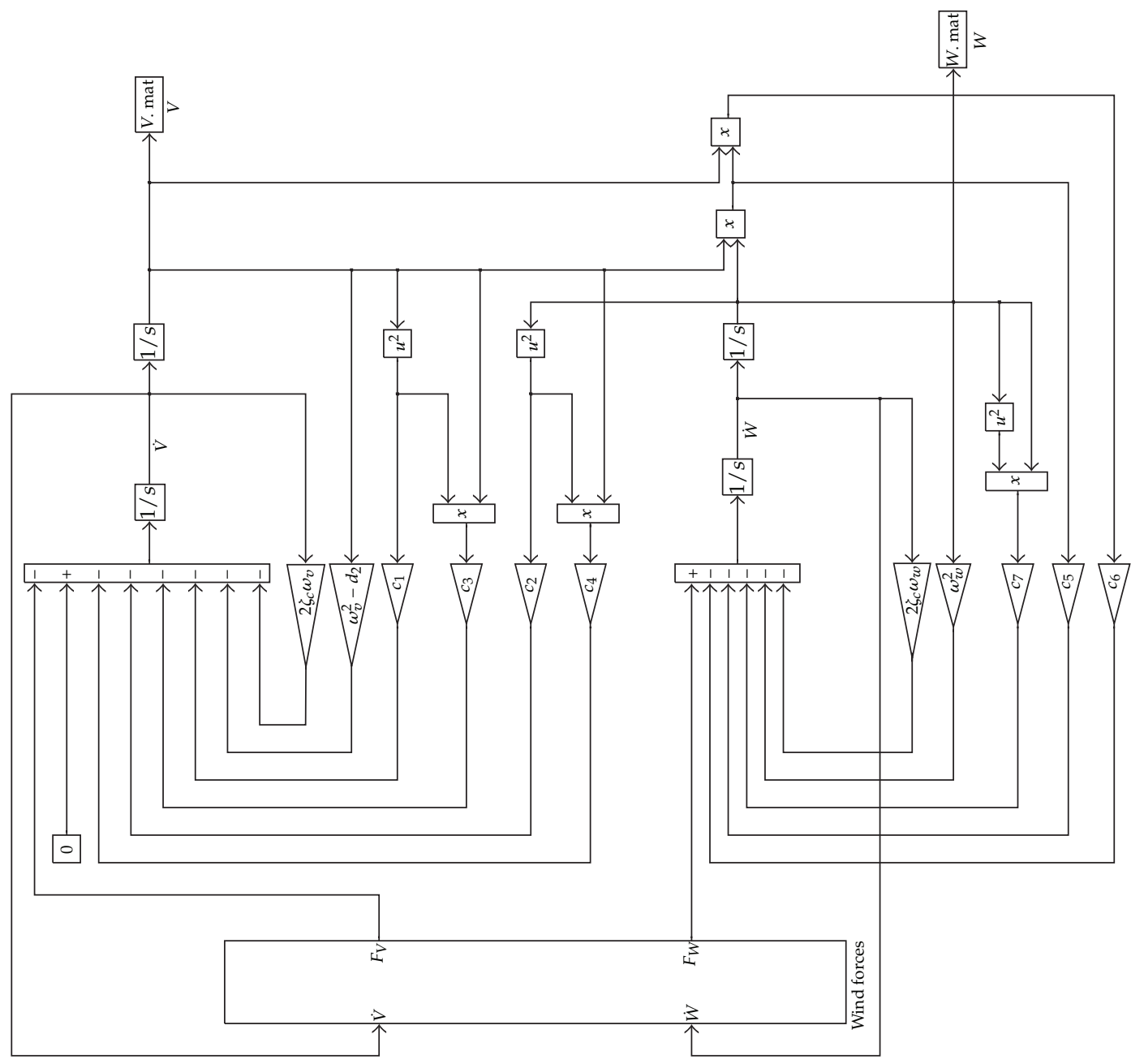

Figure 4: SIMULINK model of the suspended cable.

\subsection{Simulation Results of the Uncontrolled Suspension Bridge}

In the case of a suspension bridge, the response of the uncontrolled suspension bridge is simulated using (2.11)-(2.13) with $c_{10}$ and $c_{11}$ set to zero. The SIMULINK model of the uncontrolled suspension bridge is shown in Figure 6.

Abdel-Rohman and Joseph [17] showed that the critical wind speed is approximately $10.4(\mathrm{~m} / \mathrm{sec})$. Therefore, we simulated the response of the uncontrolled suspended bridge at wind speed $12(\mathrm{~m} / \mathrm{sec})$ which causes galloping as shown in Figure 7 . It can be seen that the uncontrolled suspension bridge response has galloping in the vertical direction of both the cable and the bridge deck.

In order to suppress galloping due to wind forces at mean wind speed $U_{0}=$ $12(\mathrm{~m} / \mathrm{sec})$, in the cable and bridge vertical responses, a vertical cable between the bridge 


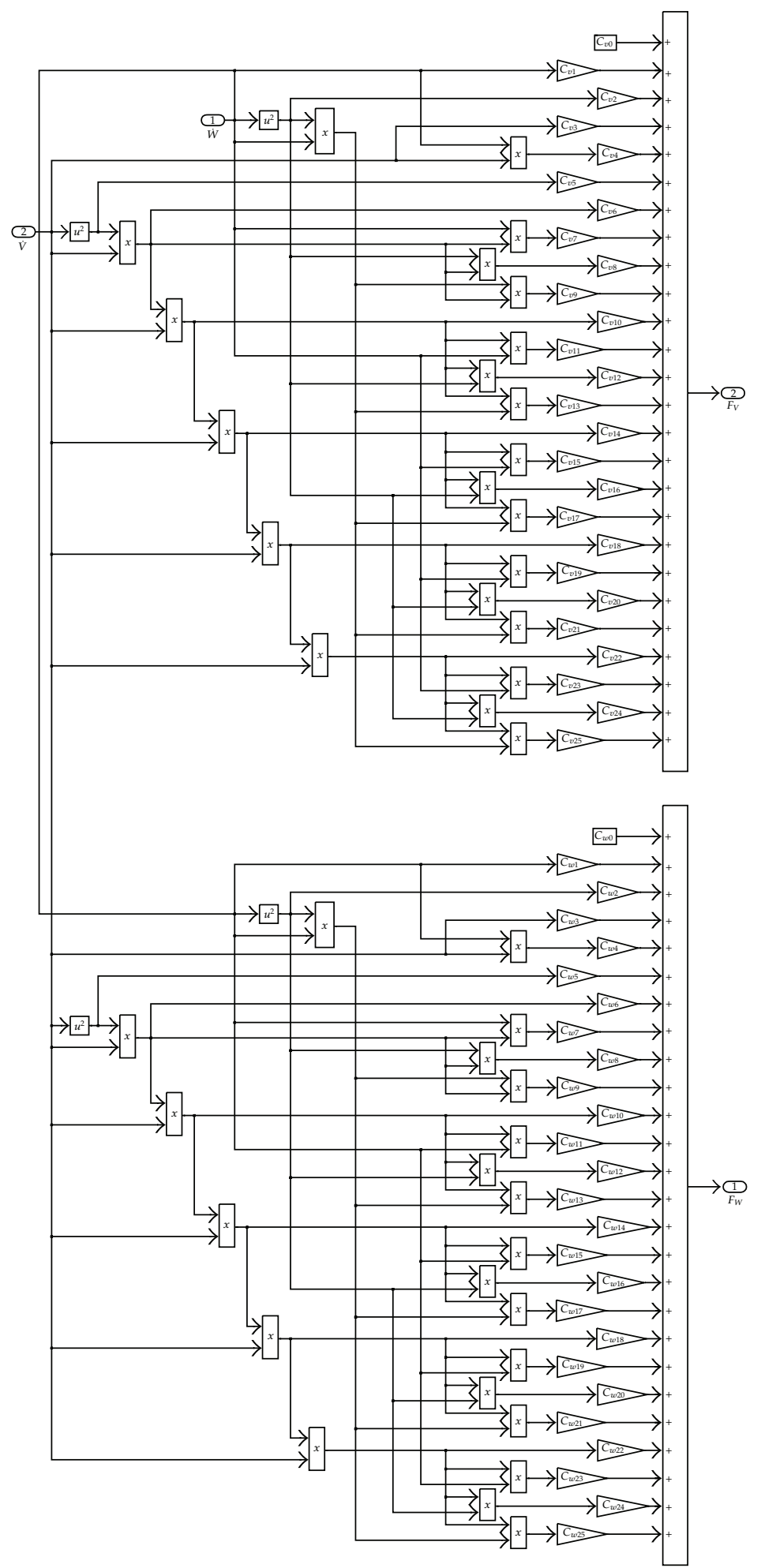

Figure 5: SIMULINK model of the wind forces. 


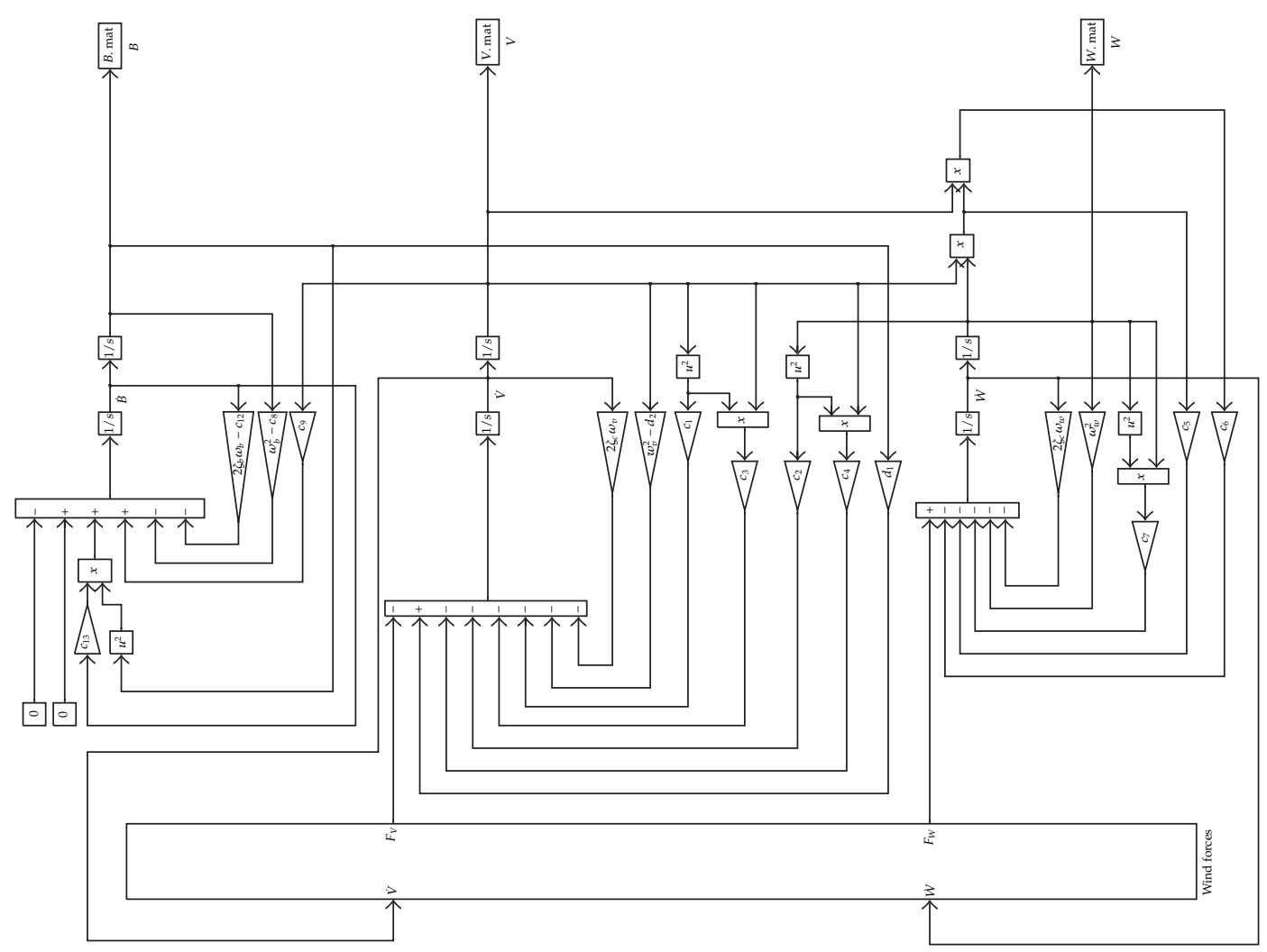

Figure 6: SIMULINK model of the uncontrolled suspension bridge.

deck and the suspended cables is used to install a hydraulic actuator able to generate the required active control force on the bridge deck. The controller will generate two equal and opposite active control forces. In the next section, a controller design based on Lyapunov theory is proposed. Two state feedback controllers are provided: the first one is a nonlinear controller and the second one is a linear controller.

\section{Controllers Design}

The suspension bridge model described by the nonlinear differential equations (2.11)-(2.13) can be represented in the following state-space form:

$$
\dot{\mathbf{x}}(t)=\mathbf{A} \mathbf{x}(t)+\mathbf{B} u(t)+\mathbf{g}_{x}(\mathbf{x}(t))+\mathbf{d}(t),
$$


where

$$
\begin{gathered}
\mathbf{x}(t)=\left[\begin{array}{l}
x_{1}(t) \\
x_{2}(t) \\
x_{3}(t) \\
x_{4}(t) \\
x_{5}(t) \\
x_{6}(t)
\end{array}\right]=\left[\begin{array}{l}
W(t) \\
\dot{W}(t) \\
V(t) \\
\dot{V}(t) \\
B(t) \\
\dot{B}(t)
\end{array}\right], \quad \mathbf{A}=\left[\begin{array}{cccccc}
0 & 1 & 0 & 0 & 0 & 0 \\
-\omega_{w}^{2}-2 \zeta_{c} \omega_{w} & \alpha & 0 & 0 & 0 \\
0 & 0 & 0 & 1 & 0 & 0 \\
0 & 0 & d_{2}-\omega_{v}^{2} & -2 \zeta_{c} \omega_{v} & d_{1} & 0 \\
0 & 0 & 0 & 0 & 0 & 1 \\
0 & 0 & c_{9} & 0 & c_{8}-\omega_{b}^{2} & -2 \zeta_{b} \omega_{b}
\end{array}\right], \\
\mathbf{B}=\left[\begin{array}{c}
0 \\
0 \\
c_{11} \\
0 \\
c_{10}
\end{array}\right], \quad \mathbf{d}(t)=\left[\begin{array}{c}
0 \\
F_{W}(t) \\
0 \\
-F_{V}(t) \\
0 \\
0
\end{array}\right], \quad \mathbf{g}_{x}(\mathbf{x}(t))=\left[\begin{array}{c}
-\alpha x_{3}-c_{7} x_{1}^{3}-\left(c_{5}+c_{6} x_{3}\right) x_{1} x_{3} \\
0 \\
-\left(c_{2}+c_{4} x_{3}\right) x_{1}^{2}-\left(c_{1}+c_{3} x_{3}\right) x_{3}^{2} \\
0 \\
0
\end{array}\right] .
\end{gathered}
$$

In order to insure the controllability of the pair $(\mathbf{A}, \mathbf{B})$, the element $(2,3)$ of the $\mathbf{A}$ matrix is set to a constant $\alpha$, and, consequently, $\alpha x_{3}$ is subtracted from the second element in the $\mathbf{g}_{x}(\mathbf{x}(t))$ vector.

Let

$$
\mathbf{g}(\mathbf{x}, t)=\mathbf{g}_{x}(\mathbf{x}(t))+\mathbf{d}(t) .
$$

Hence, the equation of the system in (4.1) can be written as

$$
\dot{\mathbf{x}}(t)=\mathbf{A x}(t)+\mathbf{B} u(t)+\mathbf{g}(\mathbf{x}, t) .
$$

The objective of this paper is to design control schemes to improve the stability of the system by suppressing the oscillations in the suspension bridge under wind excitation.

Remark 4.1. The simulation results indicate that the nonlinear function $\mathbf{g}(\mathbf{x}, t)$ in (4.4) is uniformly bounded, and hence it can be assumed that the nonlinear term $\mathbf{g}(\mathbf{x}, t)$ satisfies the following cone-bounding constraint:

$$
\|\mathbf{g}(\mathbf{x}, t)\| \leq \mu\|\mathbf{x}(t)\|,
$$

where $\mu$ is a positive scalar and $\|\cdots\|$ is the Euclidian norm of a vector.

Remark 4.2. It can be checked that the pair (A, B) in (4.4) is controllable. Hence, the poles of the closed-loop system can be selected such that the response of the linear part of the system (i.e., $\mathbf{g}(\mathbf{x}, t)=\mathbf{0})$ is as desired. 


\subsection{Design of the First Controller}

In this section, a nonlinear controller is used to suppress the oscillations in the suspension bridge due to wind loads. The control law is divided into two parts: a linear part and a nonlinear part. The linear part of the controller is designed by using the standard pole placement technique. The nonlinear part of the controller is designed to guarantee the asymptotic stability of the closed-loop system.

Let the matrix $\mathbf{A}_{c}$ be such that

$$
\mathbf{A}_{c}=\mathbf{A}-\mathbf{B K},
$$

where $\mathbf{K}$ is the feedback gain vector obtained by the standard pole placement technique. Let the symmetric positive definite matrix $\mathbf{P}_{1}$ be the solution of the following Lyapunov equation [22]:

$$
\mathbf{A}_{c}^{T} \mathbf{P}_{1}+\mathbf{P}_{1} \mathbf{A}_{c}=-\mathbf{Q}_{1}
$$

where $\mathbf{Q}_{1}=\mathbf{Q}_{1}^{T}>\mathbf{0}$.

Proposition 4.3. The control law given by the following equations (4.8)-(4.10) when applied to the suspension bridge system described by (4.4) guarantees the asymptotic stability of the closed-loop system:

$$
u=u_{L}+u_{N}
$$

with

$$
\begin{gathered}
u_{L}=-\mathbf{K} \mathbf{x}, \\
u_{N}=-\rho_{1} \operatorname{sgn}\left(\mathbf{B}^{T} \mathbf{P}_{1} \mathbf{x}\right),
\end{gathered}
$$

where $\rho_{1}$ is a positive design parameter and sgn is the sign function:

$$
\operatorname{sgn}(\sigma)= \begin{cases}+1 & \text { if } \sigma>0 \\ 0 \quad & \text { if } \sigma=0 \\ -1 & \text { if } \sigma<0\end{cases}
$$

Proof. Using (4.4), (4.8), and (4.9), it follows that

$$
\begin{aligned}
\dot{\mathbf{x}} & =\mathbf{A} \mathbf{x}+\mathbf{B}\left(-\mathbf{K} \mathbf{x}+u_{N}\right)+\mathbf{g}(\mathbf{x}, t) \\
& =(\mathbf{A}-\mathbf{B} \mathbf{K}) \mathbf{x}+\mathbf{B} u_{N}+\mathbf{g}(\mathbf{x}, t) \\
& =\mathbf{A}_{c} \mathbf{x}+\mathbf{B} u_{N}+\mathbf{g}(\mathbf{x}, t) .
\end{aligned}
$$


Consider the following Lyapunov function candidate:

$$
V_{1}=\mathbf{x}^{T} \mathbf{P}_{1} \mathbf{x}
$$

Note that $V_{1}>0$ for $\mathbf{x} \neq \mathbf{0}$ and $V_{1}=0$ for $\mathbf{x}=\mathbf{0}$. Taking the derivative of $V_{1}$ with respect to time and using (4.12), (4.10), (4.7), and (4.5), it follows that

$$
\begin{aligned}
\dot{V}_{1} & =\dot{\mathbf{x}}^{T} \mathbf{P}_{1} \mathbf{x}+\mathbf{x}^{T} \mathbf{P}_{1} \dot{\mathbf{x}} \\
& =\left(\mathbf{A}_{c} \mathbf{x}+\mathbf{B} u_{N}+\mathbf{g}(\mathbf{x}, t)\right)^{T} \mathbf{P}_{1} \mathbf{x}+\mathbf{x}^{T} \mathbf{P}_{1}\left(\mathbf{A}_{c} \mathbf{x}+\mathbf{B} u_{N}+\mathbf{g}(\mathbf{x}, t)\right) \\
& =\mathbf{x}^{T}\left(\mathbf{A}_{c}^{T} \mathbf{P}_{1}+\mathbf{P}_{1} \mathbf{A}_{c}\right) \mathbf{x}+2 \mathbf{x}^{T} \mathbf{P}_{1} \mathbf{B} u_{N}+2 \mathbf{g}(\mathbf{x}, t)^{T} \mathbf{P}_{1} \mathbf{x} \\
& =-\mathbf{x}^{T} \mathbf{Q}_{1} \mathbf{x}+2 \mathbf{x}^{T} \mathbf{P}_{1} \mathbf{B} u_{N}+2 \mathbf{g}(\mathbf{x}, t)^{T} \mathbf{P}_{1} \mathbf{x} \\
& =-\mathbf{x}^{T} \mathbf{Q}_{1} \mathbf{x}+2 \mathbf{x}^{T} \mathbf{P}_{1} \mathbf{B}\left(-\rho_{1} \operatorname{sgn}\left(\mathbf{B}^{T} \mathbf{P}_{1} \mathbf{x}\right)\right)+2 \mathbf{g}(\mathbf{x}, t)^{T} \mathbf{P}_{1} \mathbf{x} \\
& \leq-\lambda_{\min }\left(\mathbf{Q}_{1}\right)\|\mathbf{x}\|^{2}+2 \mu \lambda_{\max }\left(\mathbf{P}_{1}\right)\|\mathbf{x}\|^{2}-2 \rho_{1} \mathbf{x}^{T} \mathbf{P}_{1} \mathbf{B} \frac{\mathbf{B}^{T} \mathbf{P}_{1} \mathbf{x}}{\left|\mathbf{B}^{T} \mathbf{P}_{1} \mathbf{x}\right|} \\
& =-\lambda_{\min }\left(\mathbf{Q}_{1}\right)\|\mathbf{x}\|^{2}+2 \mu \lambda_{\max }\left(\mathbf{P}_{1}\right)\|\mathbf{x}\|^{2}-2 \rho_{1}\left|\mathbf{B}^{T} \mathbf{P}_{1} \mathbf{x}\right| \\
& \leq-\left(\lambda_{\min }\left(\mathbf{Q}_{1}\right)-2 \mu \lambda_{\max }\left(\mathbf{P}_{1}\right)\right)\|\mathbf{x}\|^{2},
\end{aligned}
$$

where $\lambda_{\min }$ and $\lambda_{\max }$ are the minimum and maximum eigenvalues of a matrix, respectively.

Therefore, it can be concluded that $\dot{V}_{1}<0$ if the matrices $\mathbf{P}_{1}$ and $\mathbf{Q}_{1}$ are selected such $\left(\lambda_{\min }\left(\mathbf{Q}_{1}\right)-2 \mu \lambda_{\max }\left(\mathbf{P}_{1}\right)\right)>0$. Hence, the control scheme given by Proposition 4.3 guarantees the asymptotic stability of the closed-loop system.

\subsection{Design of the Second Controller}

To simplify the computations involved in the implementation of the first controller, a linear controller is designed for the suspension bridge under wind loads as described by (4.4). Again, the control law is divided into two parts. The first part of the controller is designed by using the pole placement technique. The second part of the controller is designed to guarantee the asymptotic stability of the closed-loop system.

Define the matrix $\mathbf{A}_{c}$ is such that

$$
\mathbf{A}_{c}=\mathbf{A}-\mathbf{B K} \text {. }
$$

Let the symmetric positive definite matrix $\mathbf{P}_{2}$ be the solution of the following Lyapunov equation:

$$
\mathbf{A}_{c}^{T} \mathbf{P}_{2}+\mathbf{P}_{2} \mathbf{A}_{c}=-\mathbf{Q}_{2}
$$


where $\mathbf{Q}_{2}=\mathbf{Q}_{2}^{T}>\mathbf{0}$. Also, let a positive design parameter $\gamma_{2}$ be such that

$$
\gamma_{2} \geq \frac{\lambda_{\max }\left(\mathbf{P}_{2}\right)}{\lambda_{\min }\left(\mathbf{P}_{2} \mathbf{B B}^{T} \mathbf{P}_{2}\right)} \mu .
$$

Proposition 4.4. The control law given by (4.18)-(4.20) when applied to the suspension bridge system described in (4.4) guarantees the asymptotic stability of the system:

$$
u=u_{L 1}+u_{L 2}
$$

with

$$
\begin{gathered}
u_{L 1}=-\mathbf{K} \mathbf{x}, \\
u_{L 2}=-\gamma_{2} \mathbf{B}^{T} \mathbf{P}_{2} \mathbf{x} .
\end{gathered}
$$

Proof. Using (4.4), (4.18), and (4.19), it follows that

$$
\begin{aligned}
\dot{\mathbf{x}} & =\mathbf{A} \mathbf{x}+\mathbf{B}\left(-\mathbf{K} \mathbf{x}+u_{L 2}\right)+\mathbf{g}(\mathbf{x}, t) \\
& =(\mathbf{A}-\mathbf{B} \mathbf{K}) \mathbf{x}+\mathbf{B} u_{L 2}+\mathbf{g}(\mathbf{x}, t) \\
& =\mathbf{A}_{c} \mathbf{x}+\mathbf{B} u_{L 2}+\mathbf{g}(\mathbf{x}, t) .
\end{aligned}
$$

Consider the following Lyapunov function candidate:

$$
V_{2}=\mathbf{x}^{T} \mathbf{P}_{2} \mathbf{x}
$$

Note that $V_{2}>0$ for $\mathbf{x} \neq \mathbf{0}$ and $V_{2}=0$ for $\mathbf{x}=\mathbf{0}$. Taking the derivative of $V_{2}$ with respect to time and using (4.21), (4.20), (4.16), and (4.5), it follows that

$$
\begin{aligned}
\dot{V}_{2} & =\dot{\mathbf{x}}^{T} \mathbf{P}_{2} \mathbf{x}+\mathbf{x}^{T} \mathbf{P}_{2} \dot{\mathbf{x}} \\
& =\left(\mathbf{A}_{c} \mathbf{x}+\mathbf{B} u_{L 2}+\mathbf{g}(\mathbf{x}, t)\right)^{T} \mathbf{P}_{2} \mathbf{x}+\mathbf{x}^{T} \mathbf{P}_{2}\left(\mathbf{A}_{c} \mathbf{x}+\mathbf{B} u_{L 2}+\mathbf{g}(\mathbf{x}, t)\right) \\
& =\mathbf{x}^{T}\left(\mathbf{A}_{c}^{T} \mathbf{P}_{2}+\mathbf{P}_{2} \mathbf{A}_{c}\right) \mathbf{x}+2 \mathbf{g}(\mathbf{x}, t)^{T} \mathbf{P}_{2} \mathbf{x}+2 \mathbf{x}^{T} \mathbf{P}_{2} \mathbf{B} u_{L 2} \\
& =-\mathbf{x}^{T} \mathbf{Q}_{2} \mathbf{x}+2 \mathbf{g}(\mathbf{x}, t)^{T} \mathbf{P}_{2} \mathbf{x}+2 \mathbf{x}^{T} \mathbf{P}_{2} \mathbf{B} u_{L 2} \\
& =-\mathbf{x}^{T} \mathbf{Q}_{2} \mathbf{x}+2 \mathbf{g}(\mathbf{x}, t)^{T} \mathbf{P}_{2} \mathbf{x}+2 \mathbf{x}^{T} \mathbf{P}_{2} \mathbf{B}\left(-\gamma_{2} \mathbf{B}^{T} \mathbf{P}_{2} \mathbf{x}\right) \\
& \leq-\mathbf{x}^{T} \mathbf{Q}_{2} \mathbf{x}+2 \mu\left\|\mathbf{P}_{2} \mathbf{x}\right\|\|\mathbf{x}\|-2 \gamma_{2} \mathbf{x}^{T} \mathbf{P}_{2} \mathbf{B} \mathbf{B}^{T} \mathbf{P}_{2} \mathbf{x}
\end{aligned}
$$


Table 1: Data for the great belt suspension bridge.

\begin{tabular}{|c|c|c|c|c|c|}
\hline \multicolumn{2}{|c|}{ Bridge deck parameters } & \multicolumn{2}{|c|}{ Cable parameters } & \multicolumn{2}{|c|}{ Wind parameters } \\
\hline Span, $L$ & $2500 \mathrm{~m}$ & $\begin{array}{l}\text { Suspended } \\
\text { length, } l\end{array}$ & $2573 \mathrm{~m}$ & $\begin{array}{c}\text { Air density, } \\
\rho\end{array}$ & $1.25 \mathrm{Kg} / \mathrm{m}^{3}$ \\
\hline Deck mass, $m_{b}$ & $14908 \mathrm{Kg} / \mathrm{m}$ & Cable mass, $m_{c}$ & $4396 \mathrm{Kg} / \mathrm{m}$ & $H^{*}$ & 1.7 \\
\hline Width, $B_{B}$ & $27 \mathrm{~m}$ & Cable sag, $y_{c}$ & $265 \mathrm{~m}$ & $\varepsilon$ & 100 \\
\hline Flexural rigidity, $E I$ & $2.4 \times 10^{11} \mathrm{~N} \cdot \mathrm{m}^{2}$ & $\begin{array}{c}\text { Cross-sectional } \\
\text { area, } A\end{array}$ & $0.56 \mathrm{~m}^{2}$ & & \\
\hline $\begin{array}{l}\text { Stiffness of vertical } \\
\text { hangers, } k_{i}\end{array}$ & $\begin{array}{c}10^{6} \mathrm{~N} / \mathrm{m} \text { (placed } \\
\text { at every } 10 \mathrm{~m})\end{array}$ & $\begin{array}{l}\text { Young's modulus } \\
\text { of elasticity, } E\end{array}$ & $2.1 \times 10^{11} \mathrm{~N} / \mathrm{m}^{2}$ & & \\
\hline Damping ratio, $\zeta_{b}$ & 0.01 & Damping ratio, $\zeta_{c}$ & 0.001 & & \\
\hline
\end{tabular}

The parameters $H^{*}$ and $\varepsilon$ are the aerodynamic coefficients which are usually determined experimentally from wind tunnel tests. In this paper, we used the values of these parameters from [23].

$$
\begin{aligned}
& \leq-\mathbf{x}^{T} \mathbf{Q}_{2} \mathbf{x}+2 \mu \lambda_{\max }\left(\mathbf{P}_{2}\right)\|\mathbf{x}\|^{2}-2 \gamma_{2} \mathbf{x}^{T} \mathbf{P}_{2} \mathbf{B B}^{T} \mathbf{P}_{2} \mathbf{x} \\
& \leq-\mathbf{x}^{T} \mathbf{Q}_{2} \mathbf{x}+2 \mu \lambda_{\max }\left(\mathbf{P}_{2}\right)\|\mathbf{x}\|^{2}-2 \gamma_{2} \lambda_{\min }\left(\mathbf{P}_{2} \mathbf{B} \mathbf{B}^{T} \mathbf{P}_{2}\right)\|\mathbf{x}\|^{2} \\
& =-\mathbf{x}^{T} \mathbf{Q}_{2} \mathbf{x}+2\left(\mu \lambda_{\max }\left(\mathbf{P}_{2}\right)-\gamma_{2} \lambda_{\min }\left(\mathbf{P}_{2} \mathbf{B} \mathbf{B}^{T} \mathbf{P}_{2}\right)\right)\|\mathbf{x}\|^{2} \\
& \leq-\mathbf{x}^{T} \mathbf{Q}_{2} \mathbf{x} .
\end{aligned}
$$

The choice of $\gamma_{2}$ guarantees that $\left(\mu \lambda_{\max }\left(\mathbf{P}_{2}\right)-\gamma_{2} \lambda_{\min }\left(\mathbf{P}_{2} \mathbf{B} \mathbf{B}^{T} \mathbf{P}_{2}\right)\right) \leq 0$.

Therefore, it can be concluded that $\dot{V}_{2}<0$. Hence, the control scheme given by Proposition 4.4 guarantees the asymptotic stability of the closed-loop system.

\section{Simulation Results}

The simulation results of the controlled suspension bridge using the proposed controllers are presented and discussed. The system is simulated using the SIMULINK software. The data for the suspension bridge used in [7] is used here. The details of the bridge deck and the cable and wind parameters are given in Table 1. From this table, the parameters of the model of the suspension bridge can be calculated as given in the appendix. It is worth mentioning that the torsional mode frequency which is equal to $1.276 \mathrm{rad} / \mathrm{sec}$ is more than three times greater than the frequency of the vertical bending mode of $0.404 \mathrm{rad} / \mathrm{sec}$. Thus, our assumption of ignoring the torsional frequency is reasonable.

In this example, it is assumed that the wind speed profile $U_{o}(s, t)$ is a constant and equals to the basic wind speed $U_{o}$ [17]. The coefficients $C_{w i}$ and $C_{v i}$ can then be determined as functions of the basic wind speed $U_{0}$ as given in the appendix. In all simulations, the following initial conditions are used $V(0)=W(0)=B(0)=0.1 \mathrm{~m}$ and $\dot{V}(0)=\dot{W}(0)=\dot{B}(0)=$ $0.1 \mathrm{~m} / \mathrm{sec}$. 


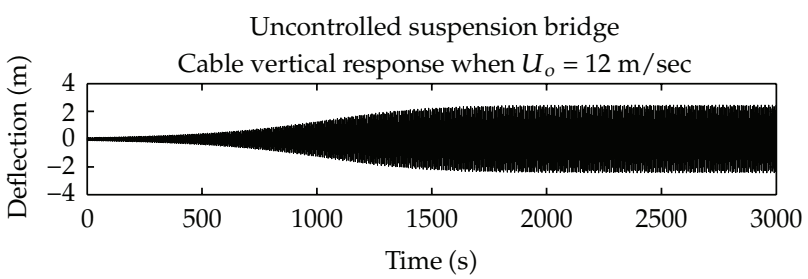

(a)

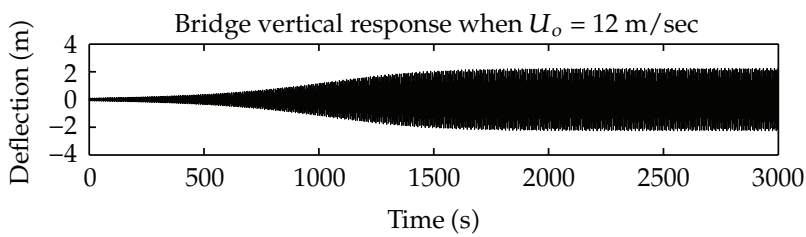

(b)

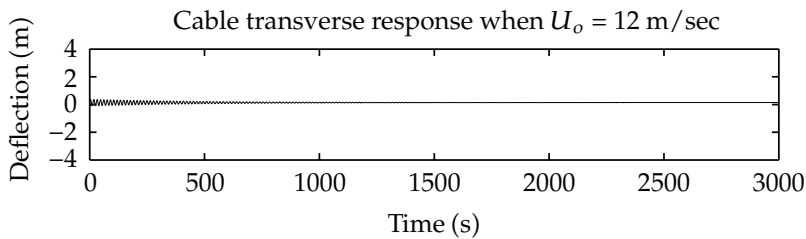

(c)

Figure 7: Uncontrolled suspension bridge response when $U_{o}=12(\mathrm{~m} / \mathrm{sec})$ : (a) cable vertical response, (b) bridge vertical response, and (c) cable transverse response.

\subsection{Simulation Results Using the First Controller}

The parameters of the first controller are $\rho_{1}=10_{6}$, the feedback gain vector $\mathbf{K}=$

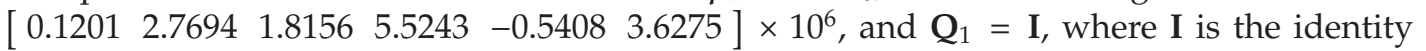
matrix of appropriate dimension. The feedback gain vector $\mathbf{K}$ is computed by MATLAB using the linear part of the system:

$$
\gg K=\text { place }(A, B, c l p),
$$

where $\mathrm{clp}$ is the desired closed-loop poles of the linear part of the system. The $\mathbf{P}_{1}$ matrix which is the solution of the Lyapunov equation in (4.7) is computed by MATLAB as follows:

$$
\gg \mathrm{P} 1=\operatorname{are}(\mathrm{A}-\mathrm{B} * \mathrm{~K}, \mathrm{zeors}(6,6), \text { eye }(6,6)) .
$$

Any wind speed greater than $10.4 \mathrm{~m} / \mathrm{sec}$ will cause galloping and can be used for simulation purposes. In this paper, a wind speed of $12 \mathrm{~m} / \mathrm{sec}$ (equivalent to $43.2 \mathrm{Km} / \mathrm{hr}$ ) is used. This wind speed equals the wind closed-loop poles of the linear suspension bridge as shown in Figure 7. The results are shown in Figure 8.

Figure 8(a) shows the vertical displacement of the suspended cable, $V(t)$. It can be seen that the oscillations in the response decay to zero in about 30 seconds. Figure $8(\mathrm{~b})$ shows the vertical displacement of the bridge deck, $B(t)$. It can be seen that the oscillations in the response decay to zero in about 30 seconds. Figure 8(c) shows the transverse displacement 


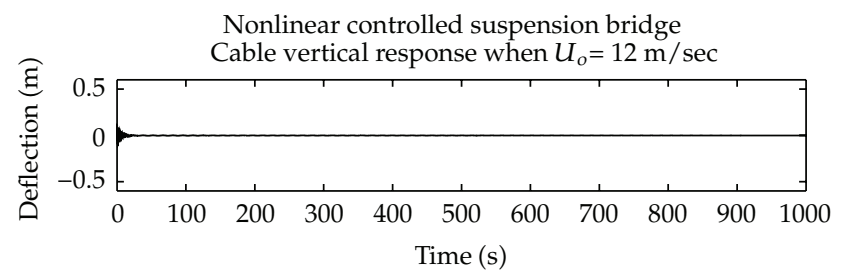

(a)

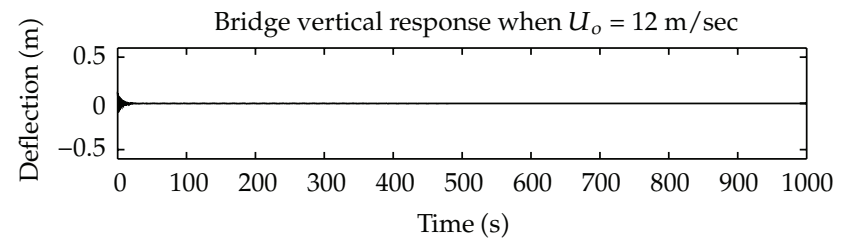

(b)

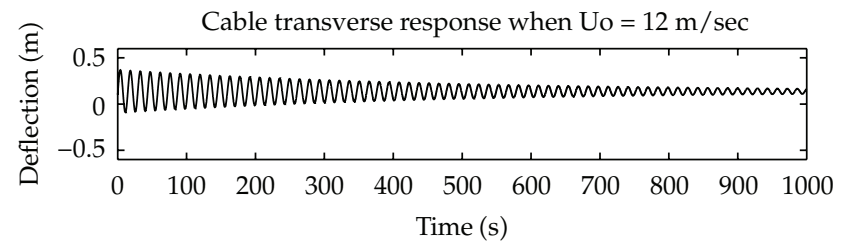

(c)

Figure 8: Suspension bridge response when using the first controller: (a) cable vertical response, (b) bridge vertical response, and (c) cable transverse response.

of the suspended cable, $W(t)$. It can be seen that the response oscillates with a slow decaying envelop as time increases. Hence, it can be concluded that the first control scheme is able to greatly reduce the oscillations in $V(t)$ and $B(t)$. Comparing Figures 7 (c) and 8 (c), we noticed that the controller did not have much of an effect on the amplitude of the transverse displacement oscillations while it reduced the frequency of the oscillations.

It is worth noting that the active control force was introduced only for the vertical displacements, and hence the oscillations of the cable and the bridge deck in this direction was suppressed, but the cable response in the transverse direction oscillates for some time before decaying to a constant amplitude. The transverse response can be improved if the bridge deck is supplemented by a horizontally sliding damper along the mean wind direction. However, for this example, the transverse response is stable irrespective of the value of the mean wind speed $U_{0}$. Moreover, the plot of the active control force versus time is shown in Figure 9. It can be seen that the force stays within a reasonable range.

\subsection{Simulation Results Using the Second Controller}

The simulation results of the controlled suspension bridge using the second controller are presented in this section. The parameters of the controller are $\gamma_{2}=10^{6}$, $\mathrm{K}$ used in first controller, and $\mathbf{Q}_{2}=\mathbf{I}$. The wind speed used in testing the performance of the proposed controller is $U_{o}=12(\mathrm{~m} / \mathrm{sec})$. The results are shown in Figure 10.

Figure 10(a) shows the vertical displacement of the suspended cable, $V(t)$. It can be seen that the oscillations in the response decay to zero in about 30 seconds. Figure 10(b) 


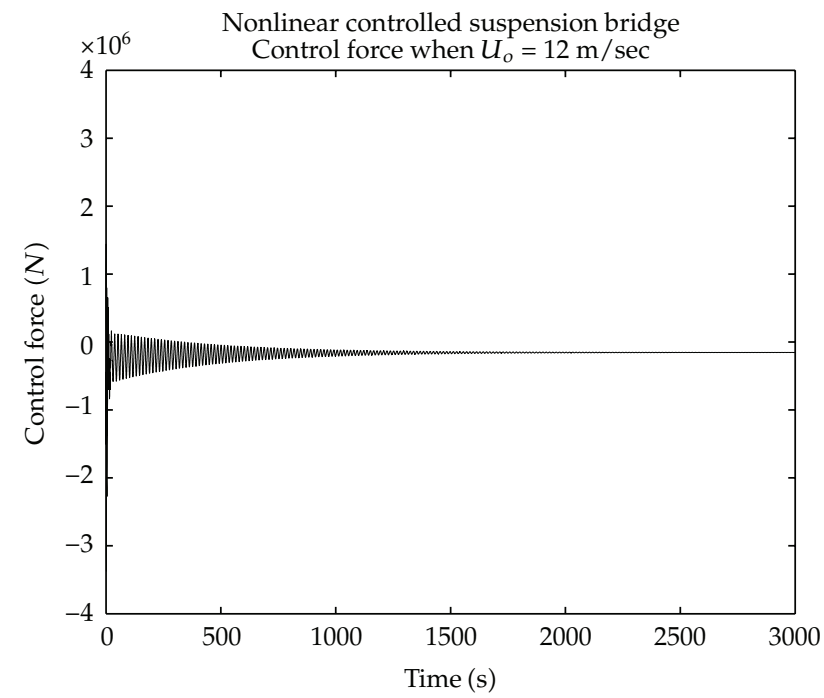

Figure 9: Response of the active control force when applied the first controller.

Linear controlled suspension bridge

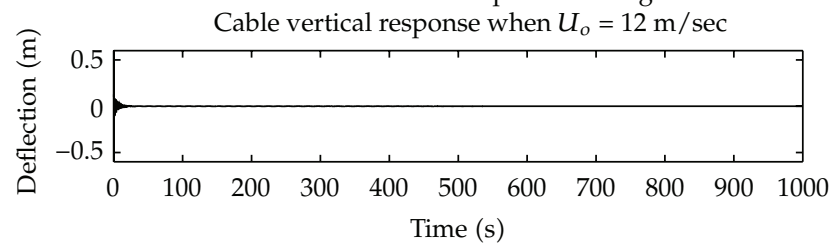

(a)

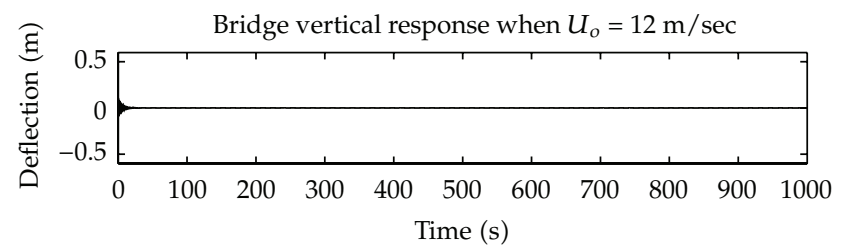

(b)

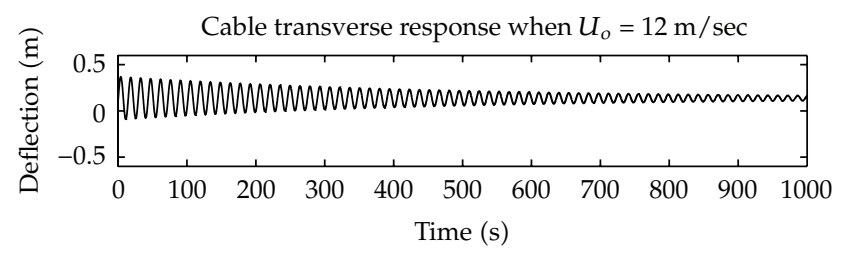

(c)

Figure 10: Suspension bridge response when using the second controller: (a) cable vertical response, (b) bridge vertical response, and (c) cable transverse response. 


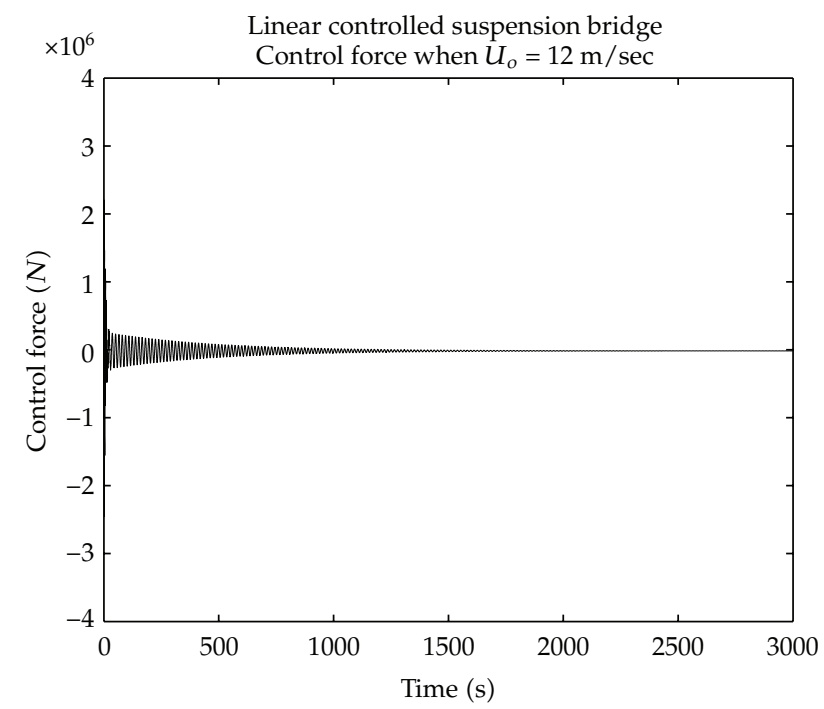

Figure 11: Response of the active control force when applied the second controller.

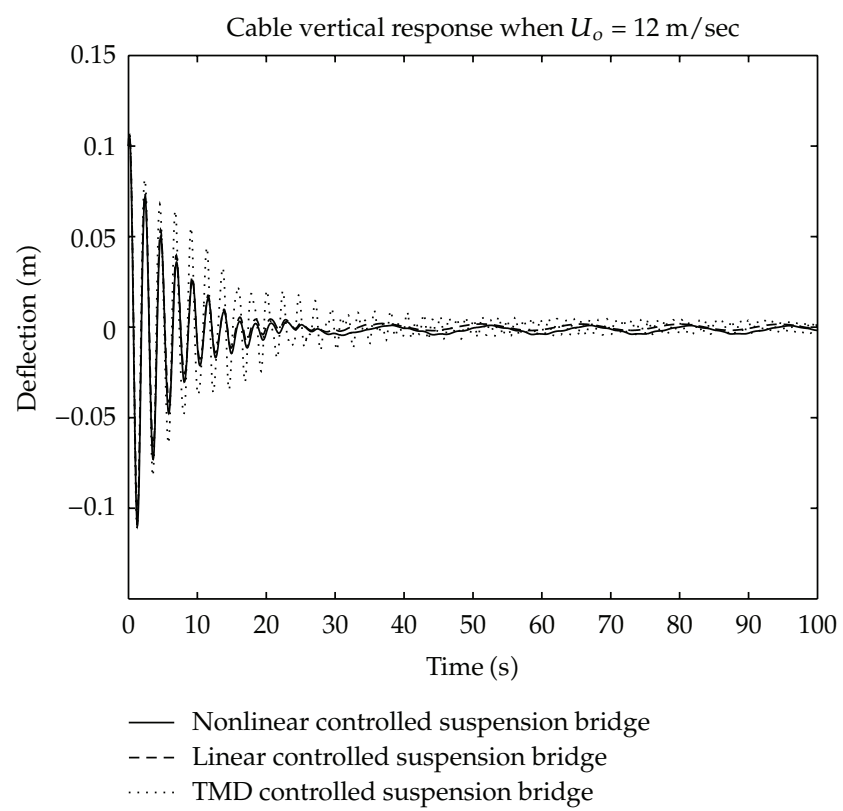

Figure 12: Vertical displacement of the suspended cable with $U_{o}=12(\mathrm{~m} / \mathrm{sec})$ when using first controller, second controller, and TMD controller.

shows the vertical displacement of the bridge deck, $B(t)$. It can be seen that the oscillations in the response decay to zero in about 30 seconds. Figure 8(c) shows the transverse displacement of the suspended cable, $W(t)$. It can be seen that the response oscillates with a slow decaying envelop as time increases. Hence, it can be concluded that the first control scheme is able to greatly reduce the oscillations in $V(t)$ and $B(t)$. Comparing Figures $7(\mathrm{c})$ and 


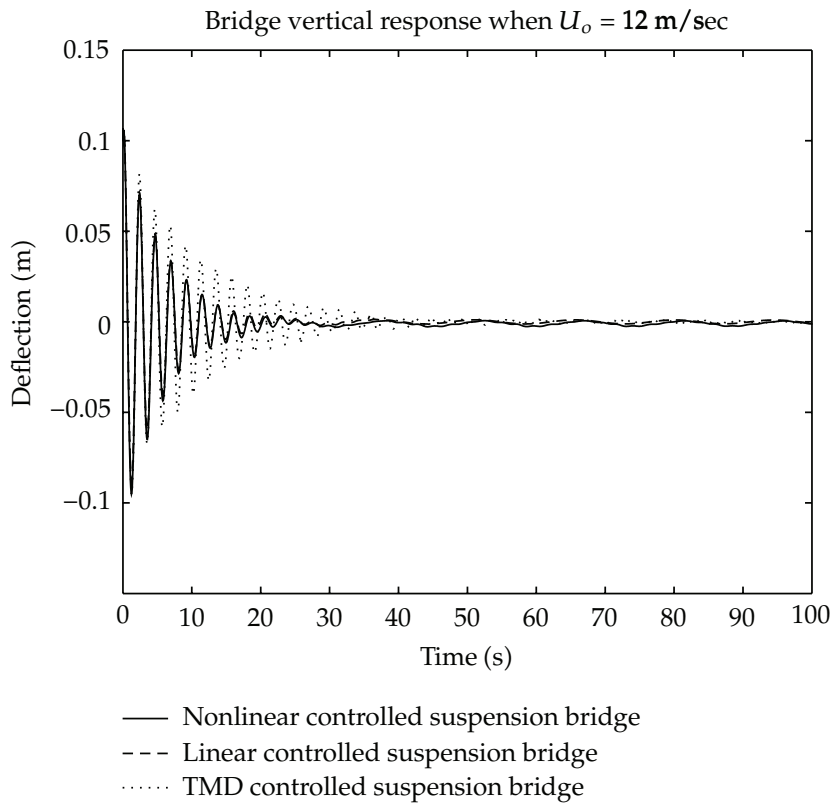

Figure 13: Vertical displacement of the bridge deck with $U_{o}=12(\mathrm{~m} / \mathrm{sec})$ when using first controller, second controller, and TMD controller.

10(c), we noticed that the controller did not have much of an effect on the amplitude of the transverse displacement oscillations.

The plot of the active control force versus time is shown in Figure 11. It can be seen that the force stays within a reasonable range.

Although we have almost the same performance when applying the two controllers, the second controller (which is linear) is much simpler in the implementation than the first controller. Thus, one can suggest applying the second controller.

\subsection{Comparison with a TMD Controller}

In this section, a comparison with the TMD controller is presented. A tuned mass damper with a weight $5 \%$ of that of the first mode mass of the bridge deck, a natural frequency of $\omega_{d}=0.97 \omega_{b}$, and a damping ratio of $20 \%$ is used. The tuned mass damper TMD is added to the bridge deck at $x_{u}=L / 2$. The wind speed used in testing the performance of the three controllers is $U_{o}=12(\mathrm{~m} / \mathrm{sec})$. The results are shown in Figures 12 and 13 .

It can be seen from these figures that the proposed controllers gave better results when compared to the passive TMD controller. The proposed controllers have smaller oscillation amplitudes and faster decay rates. For further comparison, the norms of the vertical displacements of the suspended cable and the bridge deck are computed and listed in Table 2.

It can be seen that the linear controller gives the smallest norm among the three controllers. This gives more advantage to the second controller. 
Table 2: Norms of vertical displacements of the suspension bridge.

\begin{tabular}{lccc}
\hline Controller type & Nonlinear & Linear & TMD \\
\hline$\|V(t)\|$ & 0.7420 & 0.6633 & 0.8566 \\
$\|B(t)\|$ & 0.6554 & 0.6093 & 0.7605 \\
\hline
\end{tabular}

\section{Conclusion}

The control of the nonlinear oscillations of suspension bridges due to wind loads is investigated in this paper. In order to control the vertical oscillations of the suspended cables and the bridge deck, a hydraulic actuator can be installed between the bridge deck and the suspended cables. This actuator is used to generate an active control force on the bridge deck. A linear and a nonlinear control schemes are presented to generate the active control forces. These controllers guarantee the asymptotic stability of the closed-loop system. The performance of the controlled system is investigated through simulations using the SIMULINK software. The simulation results indicate that the proposed control schemes work well. Moreover, simulation results indicated that the proposed controllers gave better results when compared to the TMD controller.

\section{Appendix}

\section{A. Parameters of the Suspension Bridge Model}

$$
\begin{gathered}
c_{1}=0.023876381 ; \quad c_{2}=-2.3130099 \times 10^{-3} ; \quad c_{3}=5.0126930 \times 10^{-4} ; \quad c_{4}=8.1873465 \times 10^{-5} ; \\
c_{5}=8.4261837 \times 10^{-3} ; \quad c_{6}=4.4516311 \times 10^{-5} ; \quad c_{7}=2.1234005 \times 10^{-5} ; \quad c_{8}=-6.7078079 ; \\
c_{9}=2.91957 ; \quad c_{10}=-2.683123 \times 10^{-8} ; \quad c_{11}=9.099181 \times 10^{-8} ; \quad c_{12}=0.4041035 ; \\
c_{13}=-0.0415744 ; \\
d_{1}=17.69253 ; \quad d_{2}=-22.6485 ; \\
\omega_{w}=0.4349(\mathrm{rad} / \mathrm{sec}) ; \quad \omega_{v}=1.1066(\mathrm{rad} / \mathrm{sec}) ; \quad \omega_{b}=2(\mathrm{rad} / \mathrm{sec}) ; \\
\alpha=10 .
\end{gathered}
$$

\section{B. Coefficients of Wind Force $F_{W}(t)$}

$$
\begin{gathered}
C_{w 0}=\frac{1.8 \times 10^{-4}}{U_{o}^{2}} ; \quad C_{w 1}=\frac{-2.83 \times 10^{-4}}{U_{o}} ; \quad C_{w 2}=1.2 \times 10^{-4} ; \quad C_{w 3}=1.78 \times 10^{-5} U_{o} \\
C_{w 4}=1.95 \times 10^{-5} U_{o}^{2} ; \quad C_{w 5}=3.47 \times 10^{-5} ; \quad C_{w 6}=\frac{-3.48 \times 10^{-6}}{U_{o}} ; \quad C_{w 7}=\frac{-3.48 \times 10^{-6}}{U_{o}^{2}} ;
\end{gathered}
$$




$$
\begin{gathered}
C_{w 8}=\frac{-3.44 \times 10^{-6}}{U_{o}^{3}} ; \quad C_{w 9}=\frac{-3.38 \times 10^{-6}}{U_{o}^{4}} ; \quad C_{w 10}=\frac{-4.63 \times 10^{-6}}{U_{o}^{2}} ; \quad C_{w 11}=\frac{-9 \times 10^{-6}}{U_{o}^{3}} ; \\
C_{w 12}=\frac{-1.32 \times 10^{-5}}{U_{o}^{4}} ; \quad C_{w 13}=\frac{-1.73 \times 10^{-5}}{U_{o}^{5}} ; \quad C_{w 14}=\frac{1.62 \times 10^{-7}}{U_{o}^{3}} ; \quad C_{w 15}=\frac{4.82 \times 10^{-7}}{U_{o}^{4}} ; \\
C_{w 16}=\frac{1.62 \times 10^{-7}}{U_{o}^{3}} ; \quad C_{w 17}=\frac{1.56 \times 10^{-6}}{U_{o}^{6}} ; \quad C_{w 18}=\frac{10^{-7}}{U_{o}^{4}} ; \quad C_{w 19}=\frac{3.95 \times 10^{-7}}{U_{o}^{5}} ; \\
C_{w 20}=\frac{9.76 \times 10^{-7}}{U_{o}^{6}} ; \quad C_{w 21}=\frac{1.93 \times 10^{-6}}{U_{o}^{7}} ; \quad C_{w 22}=\frac{-2.25 \times 10^{-9}}{U_{o}^{5}} ; \quad C_{w 23}=\frac{-1.11 \times 10^{-8}}{U_{o}^{6}} ; \\
C_{v 24}=\frac{-3.3 \times 10^{-8}}{U_{o}^{7}} ; \quad C_{v 25}=\frac{-7.61 \times 10^{-8}}{U_{o}^{8}} .
\end{gathered}
$$

\section{Coefficients of Wind Force $F_{V}(t)$}

$$
\begin{gathered}
C_{v 0}=-8.62 \times 10^{-6} U_{o}^{2} ; \quad C_{v 1}=2.73 \times 10^{-5} U_{o} ; \quad C_{v 2}=-1.5 \times 10^{-5} ; \quad C_{v 3}=-1.64 \times 10^{-4} U_{o} ; \\
C_{v 4}=1.41 \times 10^{-4} ; \quad C_{v 5}=2.89 \times 10^{-5} ; \quad C_{v 6}=\frac{1.55 \times 10^{-4}}{U_{o}} ; \quad C_{v 7}=\frac{1.49 \times 10^{-4}}{U_{o}^{2}} ; \\
C_{v 8}=\frac{1.45 \times 10^{-4}}{U_{o}^{3}} ; \quad C_{v 9}=\frac{1.41 \times 10^{-4}}{U_{o}^{4}} ; \quad C_{v 10}=\frac{-7.23 \times 10^{-6}}{U_{o}^{2}} ; \quad C_{v 11}=\frac{-1.44 \times 10^{-5}}{U_{o}^{3}} ; \\
C_{v 12}=\frac{-2.14 \times 10^{-5}}{U_{o}^{4}} ; \quad C_{v 13}=\frac{-2.81 \times 10^{-5}}{U_{o}^{5}} ; \quad C_{v 14}=\frac{-3.32 \times 10^{-5}}{U_{o}^{3}} ; \quad C_{v 15}=\frac{-9.77 \times 10^{-5}}{U_{o}^{4}} ; \\
C_{v 16}=\frac{-1.92 \times 10^{-4}}{U_{o}^{5}} ; \quad C_{v 17}=\frac{-3.16 \times 10^{-5}}{U_{o}^{6}} ; \quad C_{v 18}=\frac{1.74 \times 10^{-7}}{U_{o}^{4}} ; \quad C_{v 19}=\frac{6.9 \times 10^{-7}}{U_{o}^{5}} ; \\
C_{v 20}=\frac{1.71 \times 10^{-6}}{U_{o}^{6}} ; \quad C_{v 21}=\frac{3.38 \times 10^{-6}}{U_{o}^{7}} ; \quad C_{v 22}=\frac{7.93 \times 10^{-7}}{U_{o}^{5}} ; \quad C_{v 23}=\frac{3.92 \times 10^{-6}}{U_{o}^{6}} ; \\
C_{v 24}=\frac{1.16 \times 10^{-5}}{U_{o}^{7}} ; \quad C_{v 25}=\frac{2.69 \times 10^{-5}}{U_{o}^{8}} .
\end{gathered}
$$

\section{References}

[1] J. Cheng, J.-J. Jiang, R.-C. Xiao, and H.-F. Xiang, "Nonlinear aerostatic stability analysis of Jiang Yin suspension bridge," Engineering Structures, vol. 24, no. 6, pp. 773-781, 2002.

[2] M. Abdel-Rohman and B. F. Spencer, "Control of wind-induced nonlinear oscillations in suspended cables," Nonlinear Dynamics, vol. 37, no. 4, pp. 341-355, 2004.

[3] C. S. Cai and S. R. Chen, "Framework of vehicle-bridge-wind dynamic analysis," Journal of Wind Engineering and Industrial Aerodynamics, vol. 92, no. 7-8, pp. 579-607, 2004. 
[4] N. B. Almutairi, M. F. Hassan, M. Abdel-Rohman, and M. Terro, "Control of suspension bridge nonlinear vibrations due to moving loads," Journal of Engineering Mechanics, vol. 132, no. 6, pp. 659670, 2006.

[5] N. Hoang and Y. Fujino, "Multi-mode control performance of nonlinear dampers in stay cable vibrations," Structural Control and Health Monitoring, vol. 16, no. 7-8, pp. 860-868, 2009.

[6] C. Zhang, L. Li, and J. Ou, "Swinging motion control of suspended structures: principles and applications," Structural Control and Health Monitoring, vol. 17, no. 5, pp. 549-562, 2010.

[7] T. Huynh and P. Thoft-Christensen, "Suspension bridge flutter for girders with separate control flaps," Journal of Bridge Engineering, vol. 6, no. 3, pp. 168-175, 2001.

[8] M. Abdel-Rohman, "Effect of unsteady wind flow on galloping of tall prismatic structures," Nonlinear Dynamics, vol. 26, no. 3, pp. 231-252, 2001.

[9] A. H. Nayfeh and M. Abdel-Rohman, "Analysis of wind excited vibrations of cantilever beams using the method of multiple scales," Journal of Sound and Vibration, vol. 144, pp. 87-93, 1991.

[10] P. Yu, Y. M. Desai, A. H. Shah, and N. Popplewell, "Three-degree-of-freedom model for galloping. Part 1: formulation," Journal of Engineering Mechanics, vol. 119, no. 12, pp. 2404-2425, 1993.

[11] P. Yu, Y. M. Desai, N. Popplewell, and A. H. Shah, "Three-degree-of-freedom model for galloping. Part 2: solutions," Journal of Engineering Mechanics, vol. 119, no. 12, pp. 2426-2448, 1993.

[12] A. Luongo and G. Piccardo, "Non-linear galloping of sagged cables in 1:2 internal resonance," Journal of Sound and Vibration, vol. 214, no. 5, pp. 915-940, 1998.

[13] M. Abdel-Rohman and H. Askar, "Control by passive TMD of wind-induced nonlinear vibrations in cable stayed bridges," Journal of Vibration and Control, vol. 2, no. 2, pp. 251-267, 1996.

[14] Y. L. Xu and Z. Yu, "Vibration of inclined sag cables with oil dampers in cable-stayed bridges," Journal of Bridge Engineering, vol. 3, no. 4, pp. 194-203, 1998.

[15] E. A. Johnson, B. F. Spencer Jr., and Y. Fujino, "Semi active damping in stay cables-a preliminary study," in Proceedings of the 17th International Modal Analysis Conference, pp. 417-423, Kissimmee, Fla, USA, February 1999.

[16] M. Gu, S. R. Chen, and C. C. Chang, "Control of wind-induced vibrations of long-span bridges by semi-active lever-type TMD," Journal of Wind Engineering and Industrial Aerodynamics, vol. 90, no. 2, pp. 111-126, 2002.

[17] M. Abdel-Rohman and M. J. Joseph, "Control of wind-induced nonlinear oscillations in suspension bridges using a semi-active tuned mass damper," Journal of Vibration and Control, vol. 12, no. 10, pp. 1049-1080, 2006.

[18] R. A. Cárdenas, F. J. Viramontes, A. González, and G. Ruiz, “Analysis for the optimal location of cable damping systems on stayed bridges," Nonlinear Dynamics, vol. 52, no. 4, pp. 347-359, 2008.

[19] G. V. Rao and R. N. Iyengar, "Internal resonance and nonlinear response of a cable under periodic excitation," Journal of Sound and Vibration, vol. 149, pp. 25-41, 1991.

[20] M. Irvine, Cable Structures, Dover, New York, NY, USA, 1992.

[21] M. Abdel-Rohman, "Design of optimal observers for structural control," Journal of Control Theory and Applications, vol. 131, no. 4, pp. 158-163, 1984.

[22] D. S. Naidu, Optimal Control Systems, CRC Press, Boca Raton, Fla, USA, 2003.

[23] E. Simiu and R. H. Scanlan, Wind Effects on Structures: Fundamentals and Applications to Design, Dover, Mineola, NY, USA, 3rd edition, 2008. 


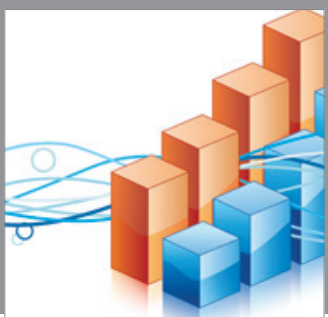

Advances in

Operations Research

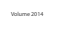

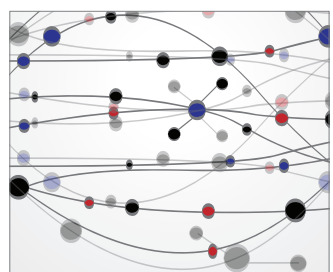

\section{The Scientific} World Journal
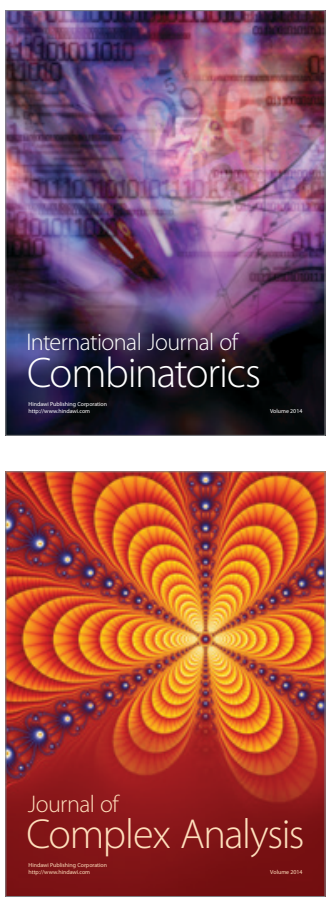

International Journal of

Mathematics and

Mathematical

Sciences
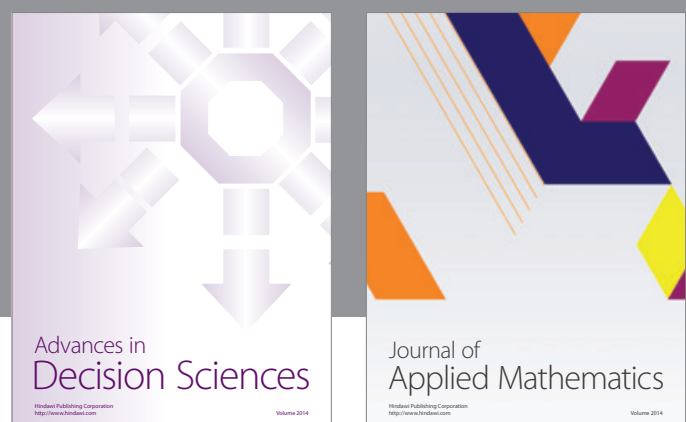

Journal of

Applied Mathematics
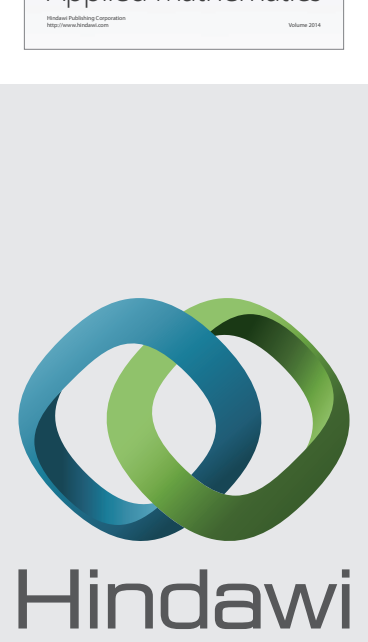

Submit your manuscripts at http://www.hindawi.com
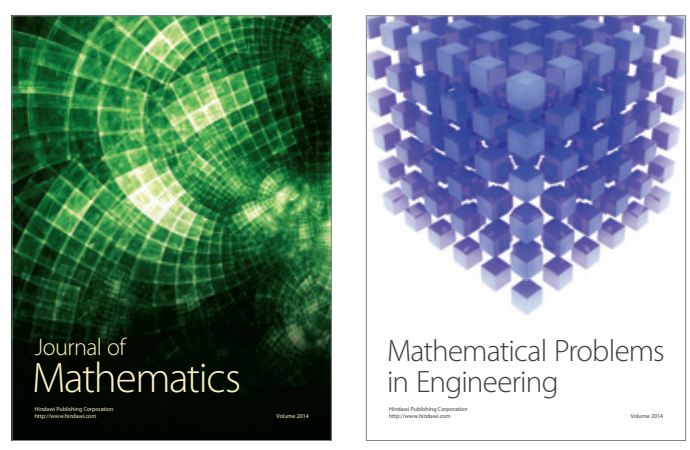

Mathematical Problems in Engineering
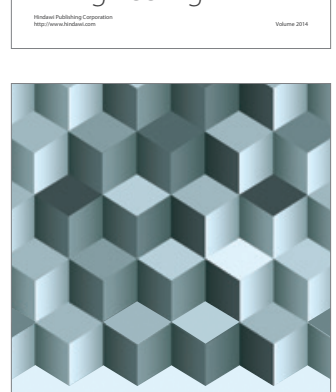

Journal of

Function Spaces
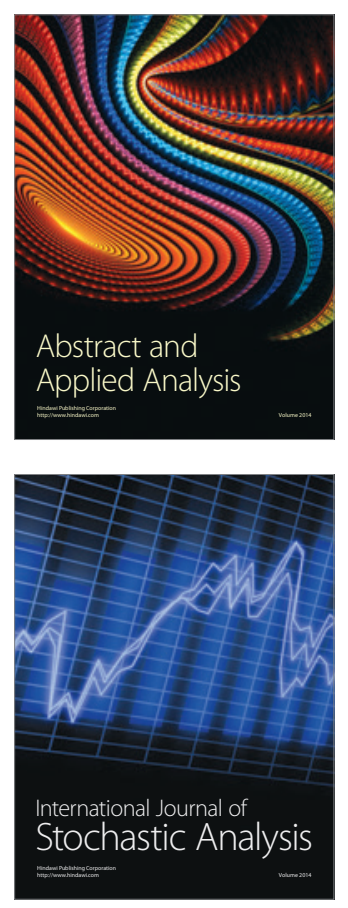

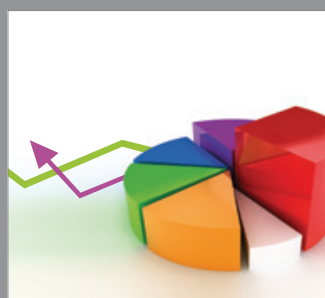

ournal of

Probability and Statistics

Promensencen
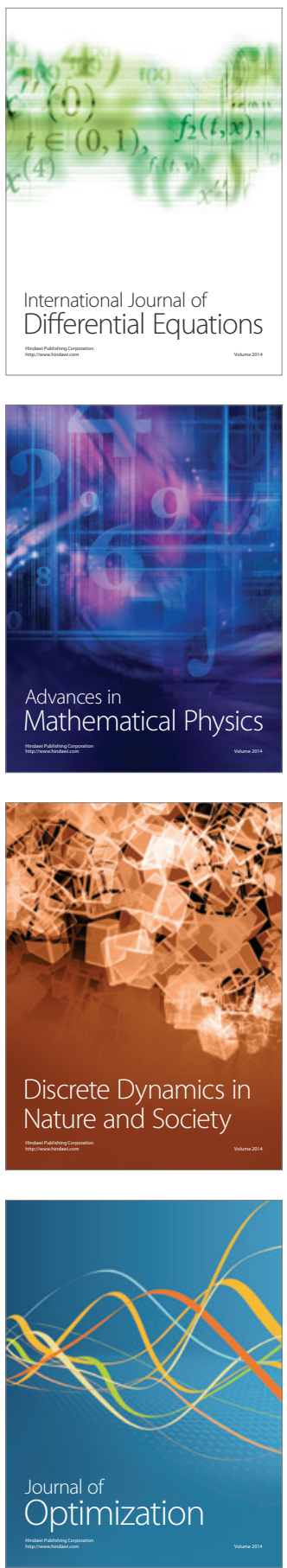